HeNRiksen, S. D. (1952). J. gen. Microbiol. 6, 318-328.

\title{
Moraxella: Classification and Taxonomy
}

\author{
By S. D. HENRIKSEN \\ Department of Bacteriology, State Institute for Public Health, Oslo, Norway
}

\begin{abstract}
SUMMARY: Eleven strains regarded as moraxellas were studied; nine were characterized by moderate growth on the usual media, a positive oxidase reaction and sensitivity to penicillin, and six of these preferred or required a humid atmosphere when incubated at $37^{\circ}$. The classification of these strains was considered correct. Two strains did not show any of these characteristics, and it was concluded that they should not properly be classified as moraxellas.

A positive oxidase reaction, sensitivity to penicillin, and preference for a humid atmosphere at $37^{\circ}$ may be useful criteria in the classification of Moraxella. It is suggested that Moraxella may be closely related to Neisseria, and that the description of the genus and its taxonomic position should be revised in accordance with Lwoff's proposals.

Mima polymorpha var. oxidans (De Bord) is believed to belong to Moraxella, whereas other members of the tribe Mimeae (De Bord) and Bacterium anitratum (Schaub \& Hauber) are probably not closely related to Moraxella.
\end{abstract}

Lwoff (1939) proposed that the organism classified as Haemophilus duplex and some related organisms should be gathered in a new genus, Moraxella, and that this genus should be separated from the Haemophileae, as its species neither resembled the Haemophileae morphologically nor required haematin or phosphopyridinenucleotide as growth factors. These proposals were approved by Audureau (1940), who added a new species, $M$. lwoffi.

Bergey's Manual (1948) accepted Lwoff's proposal to create the genus Moraxella, but put it in the Haemophileae. The vague description of the genus-mainly morphological, which might fit almost any Gram-negative rod-indicates a lack of specific characters to differentiate it from other genera.

The present study was made to evaluate additional characters, which, added to the description, would clarify the taxonomy of the genus and show its relationship to organisms such as Mimeae (De Bord, 1939), Bacterium anitratum (Schaub \& Hauber, 1948) and Neisseria, all of which appeared to resemble Moraxella in some respects.

\section{MATERIAL AND METHODS}

Of the strains isolated in this laboratory, one (3452/51) was from sputum (Henriksen, 1951), three from urine $(283 / 49,6758 / 51,7146 / 51)$ and two (possibly the same strain) from throat cultures of a husband and wife (OT/51, AT/51). Type strains of some Moraxella species were received from the Institut Pasteur, Paris, through the courtesy of Dr A. Lwoff and Dr M. Piéchaud (M. lacunata 4238, Diplobacillus of Morax 260, Diplobacillus of Petit, M. lwoffi var. bacteroides and $M$. pericardite).

For comparison five strains of Neisseria pharyngis, four of the pigmented, carbohydrate-fermenting variety, and one non-pigmented, non-fermenting (N. catarrhalis), were studied (OT 2/51, OTJ 1/51, OTJ 2/51, TT/51, 26051/51). 
Customary methods were used in the study of morphological and biochemical properties of the strains. For the study of sensitivity to antibiotics, three different methods were used.

(1) A filter-paper disk method (Jensen \& Kiaer, 1948). Antibiotic solutions used to moisten the disks were: penicillin 175 units $/ \mathrm{ml}$., streptomycin $2800 \mu \mathrm{g} . / \mathrm{ml}$., sulphathiazole $6.6 \mathrm{mg}$. $/ \mathrm{ml}$., chloromycetin and aureomycin $1000 \mu \mathrm{g} . / \mathrm{ml}$. each. Incubation at $28^{\circ}$ for $48 \mathrm{hr}$.

(2) An antibiotic tablet method (Lund, Funder-Schmidt, Christensen \& Dupont, 1951). The tablets (Roskilde Medical Co. Ltd., Roskilde, Denmark), which contain the above antibiotics and also terramycin, are deposited on peptone-free $10 \%$ horse blood agar plates, which have been inoculated with a suspension of the organism to be tested. Inhibition zones are measured after incubation for 24 hr. at $37^{\circ}$ in a closed jar containing some water.

(3) Titration in $10 \%(\mathrm{v} / \mathrm{v})$ serum broth containing twofold dilutions of the antibiotics. Incubation at $28^{\circ}$ for $48 \mathrm{hr}$. Readings were made after 24 and $48 \mathrm{hr}$.

\section{RESULTS}

\section{Morphology}

The following characteristics (illustrated in Pl. 1, figs. 1-9) were observed in varying degree:

$A$ preference for arrangement in pairs. In some strains nearly all organisms were arranged in pairs, as diplococci $(283 / 49$, fig. 1) or as short diplobacilli (3452/51, fig. 2 and a dissociant strain of 283/49); in others both diplo-forms and single cells were found; short chains were seen occasionally.

Plumpness of the cells. With the exception of two (M. lwoffi var. bacteroides and $M$. pericardite) all strains had plump, broad cells, usually with obtuse or nearly square-cut ends. The breadth of the cells varied between 1 and $1.5 \mu$, although larger cells were frequent in some strains. The length varied from neisseria-like coccus-forms to long filaments. The two exceptions had small coccoid or coccobacillary cells.

Pleomorphism. Considerable variations in size and shape were frequent, although not equally marked in all strains, nor under all conditions of growth. Large swollen cells could be found in all strains: there were spherical or oval bodies, club-shaped or sausage-shaped cells or coarse filaments with fusiform swellings. The strains $\boldsymbol{M}$. lwoffi var. bacteroides and $\boldsymbol{M}$. pericardite were less pleomorphic than most other strains.

Irregular staining. The majority of the cells were Gram-negative, but some cells with very sharp outlines were strongly stained by the counter-stain, whereas others were pale. Other cells, particularly the swollen elements, showed a tendency to be Gram-positive and were purplish to violet, or contained bluish black granules after decolorization with ethanol. Thorough treatment with ethanol removed all the purple stain. On the other hand, some of the swollen cells appeared as pale 'ghost cells'.

The individual strains showed considerable variations. One (283/49) produced diplococci nearly exclusively (figs. 1 and 6) and showed a striking resemblance to $N$. gonorrhoeae; only occasional rods could be found. A dissociant, split off by this strain in the course of the work, and also strain 
3452/51 almost exclusively produced short plump, nearly square, diplobacilli (fig. 2). Strains 6768/51 (figs. 5, 9), 7146/51, OT/51 (fig. 4) and AT/51 produced mixtures of diplobacilli, diplococci and single cells, with rods predominating, whereas $\boldsymbol{M}$. pericardite and $\boldsymbol{M}$. lwoffi var. bacteroides generally produced very small coccoid and coccobacillary cells, frequently in pairs (fig. 3). Finally, strains M. lacunata 4238, Diplobacillus of Morax 260 (fig. 8) and Diplobacillus of Petit appeared to be in the $\mathbf{R}$-form and grew as chains of elongated cells or as filaments.

\section{Growth characteristics}

The strains $M$. lwoffi var. bacteroides and $M$. pericardite grew vigorously on all media. The colonies were large and butyrous, resembling those of the Enterobacteriaceae, e.g. Escherichia coli. The strain $M$. lwoffi var. bacteroides produced slightly spreading colonies. Cultures of $M$. pericardite were characterized by a marked odour, resembling that of certain pseudomonas cultures.

The other strains showed a much less vigorous and slower growth. The colonies were smaller (c. $1 \mathrm{~mm}$. or less after $24 \mathrm{hr}$.), grey or yellowish, raised, and friable or slightly viscous, like the colonies of some strains of $N$. pharyngis. A dissociant of 283/49 mentioned above, produced tiny, delicate, colourless, translucent colonies, resembling gonococcus colonies. One strain (3452/51) grew with mucoid colonies, resembling those of Klebsiella ozaenae. Finally the strains M. lacunata 4238, Diplobacillus of Morax 260, and Diplobacillus of Petit grew with very small, delicate, greyish colonies of a distinctly rough appearance.

\section{Effect of temperature and humidity}

Some of the strains (M. lacunata 4238, Diplobacillus of Morax 260, Diplobacillus of Petit, 283/49, 3452/51 and 6768/51) grew very poorly or not at all on blood agar plates incubated in an ordinary incubator at $37^{\circ}$. Growth was greatly improved by incubation in a closed jar containing some water. Growth at $28^{\circ}$ was good regardless of the humidity and all strains showed growth at a room temperature of about $20^{\circ}$, although in some cases this was extremely poor and slow. Thus this group of strains was very sensitive to a dry atmosphere at $37^{\circ}$.

Strains 7146/51, OT/51, AT/51 and $M$. pericardite grew well under all these conditions, but $M$. lwoffi var. bacteroides did not grow at $37^{\circ}$, regardless of the degree of humidity; it grew vigorously at lower temperatures, including room temperature.

\section{Growth requirements}

Growth was studied on simple and enriched media and in the defined medium containing ethanol, citrate, ammonia and inorganic salts described by Audureau (1940). The strains could be divided in several groups according to growth requirements :

(1) Grow only on media containing body fluids: $M$. lacunata 4238, Diplobacillus of Morax 260.

(2) Grow on simple meat-infusion + peptone media but not in the defined medium: Diplobacillus of Petit, 3452/51, OT/51, AT/51. 
(3) Grow on simple media; very slight but continuous growth (five transfers) in the defined medium, perceptible only as a very slight precipitate: $283 / 49$.

(4) Moderate, slow growth in the defined medium: 6768/51, 7146/51.

(5) Vigorous, rapid growth in the defined medium: $M$. pericardite, $M$. lwoffi var. bacteroides.

\section{Some biochemical reactions}

The strains M. lacunata 4238, Diplobacillus of Morax 260, and Diplobacillus of Petit liquefied coagulated serum and, to some extent, coagulated egg; the others did not. Otherwise the biochemical reactions were the same as previously reported (Lwoff, 1939; Audureau, 1940; Henriksen, 1947; Piéchaud, Piéchaud \& Second, 1951). None of the strains isolated in this laboratory fermented any of the usual carbohydrates.

All strains except $M$. pericardite and $M$. lwoffi var. bacteroides gave a positive oxidase reaction with tetramethyl-p-phenylenediamine. In some cases the reaction was as strong and rapid as in $N$. gonorrhoeae, in others it was weaker and slower. Young delicate colonies as a rule gave stronger and more rapid reactions than older and larger ones, possibly because the latter were not as wettable or as easily penetrated by the reagent.

\section{Sensitivity to antibiotics}

The results of the tests are shown in Table 1 . The strains $M$. lacunata 4238, Diplobacillus of Morax 260 and Diplobacillus of Petit, due to poor and slow growth, did not give very sharp end-points in the serial dilution tests, nor very sharp zones in the other tests. In these cases the inhibition zones were recorded as averages of several measurements, and the results were checked after additional incubation, which brought out the limits of the zones better, apparently without appreciably changing their sizes.

Table 1. Sensitivity of Moraxella and Neisseria strains to antibiotics

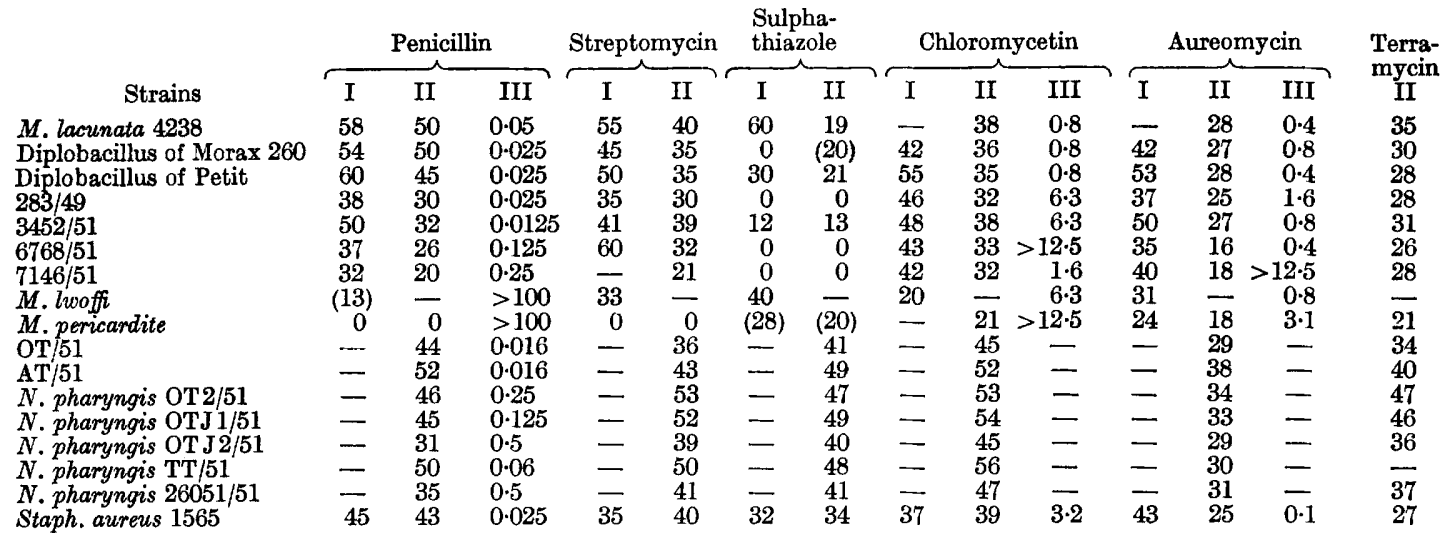

Column I: filter-paper disk method, diameter of inhibition zones in $\mathrm{mm}$.

Column II: antibiotic tablet method, diameter of inhibition zones in $\mathrm{mm}$.

Column III: titration in $10 \%$ serum broth. Lowest inhibitory concentration in $\mu \mathrm{g} . / \mathrm{mI}$. (penicillin:units/ml.).

Figures in brackets indicate zones of only partial inhibition. 
The most interesting results are those obtained with penicillin. These separate the strains into two groups; $M$. pericardite and $M$. lwoffi var. bacteroides, which were highly resistant to penicillin, in one group, and the other strains with great or moderate sensitivity, in the second. All strains were inhibited by concentrations within, or very close to, the usual therapeutic range, and all strains in the second group showed penicillin sensitivities within the range shown by various species of Neisseria.

With the strains of $N$. pharyngis there was a discrepancy between the results obtained by titration in a fluid medium and by the antibiotic tablet method. By the tablet method the strains appeared to be very sensitive to penicillin, but by the dilution method the sensitivity appeared to be only moderate. The reason for this discrepancy was not studied.

In my experience the antibiotic tablet method has shown some peculiarities, possibly due to different solubility and diffusion rates of the different antibiotics. The results obtained with penicillin, streptomycin, chloromycetin and sulphathiazole have usually been in good agreement with those obtained by other methods, but the inhibition zones obtained with terramycin and particularly with aureomycin have frequently been narrower than expected. This method should probably be considered to yield rough approximations rather than exact quantitative data.

\section{DISCUSSION}

The strains can be separated into two groups. Those of the first group are characterized by moderate growth on the usual media, colonies resembling species of Neisseria, a positive oxidase reaction, and strong to moderate sensitivity to penicillin. Several strains showed a marked preference for a humid atmosphere when cultivated at $37^{\circ}$. The individual cells are plump and broad and in some cases show a marked resemblance to Neisseria spp.

The second group, apart from some morphological and biochemical similarities, did not present these characteristics. It is doubtful whether these two groups should be classified in the same genus.

It seems reasonable to consider the oxidase-positive group, which agrees with the representatives of the type species, as moraxella strains, whereas the classification of the two remaining strains is an open question.

The description of the genus Moraxella given in Bergey's Manual, 1948, p. 590, does not allow the recognition of these two groups as none of the criteria used in separating them occurs in the description. It is difficult to assess the biological significance of the proposed new criteria, namely, oxidase reaction, penicillin sensitivity and sensitivity to a dry atmosphere, but they may be expressions of fundamental biological properties which might profitably be used in classification.

The oxidase reaction is not a common reaction and, apart from Neisseria and Moraxella, none of the recognized bacterial genera is known to give consistently positive reactions. Only occasional, often ill-defined, species outside these genera have been reported to give the reaction. In Moraxella the reaction has been reported to be positive by several authors (Oeding, 1946; Henriksen, 1947; Steen \& Berdal, 1950). 
It is commonly recognized that penicillin sensitivity is unusual in Gramnegative organisms, most of which are strongly or moderately resistant. The only important exceptions are $N$. gonorrhoeae and $N$. intracellularis. Little is known about the sensitivity of other species of Neisseria, but it seems that the non-pathogenic species are the less sensitive (Florey et al. 1949). My few strains appeared to be very sensitive when tested on a solid medium and moderately sensitive in a fluid medium, and were more sensitive than the majority of Gram-negative organisms.

The following statement by Dubos (1949) apparently might apply equally well to Moraxella: 'Although gonococci and meningococci are susceptible to both penicillin and gramicidin, this exception is correlated with the fact that the pathogenic Gram-negative cocci occupy an intermediate position between the Gram-positive organisms and the Gram-negative bacilli.'

Strains of $M$. duplex var. liquefaciens (Lwoff) isolated by Oeding (1946) and by Steen $\&$ Berdal (1950) were sensitive to 0.01 and 0.03 unit penicillin $/ \mathrm{ml}$. respectively. On the other hand, Cashell (1944) reported strains of Petit's bacillus and Morax-Axenfeld's bacillus to be insensitive in vitro, although eye inflammations were cured by local penicillin treatment. Milner (1944) and Sorsby (1945) successfully treated eye infections caused by these organisms, with penicillin.

The inability to grow in a dry atmosphere at $37^{\circ}$ does not appear to be an equally constant property, since three of nine strains were exceptions, and therefore it may not be very significant in classification. It is interesting, however, that this characteristic is a further point of resemblance to the pathogenic neisseria.

The number of strains studied is too small for far-reaching conclusions; additional strains may show a wider range of variation. If, in future work, the main points should be corroborated, the description of the genus Moraxella might perhaps be revised along the following lines:

'Plump short rods or cocci, frequently with considerable variation of the size of the cells and a tendency to produce large swollen "involution forms", predominantly occurring in pairs and occasionally short chains. Some strains show striking resemblance to neisseria. Non-motile. Gram-negative, but some cells may show a tendency to retain some of the purple stain. Aerobic. Some strains prefer or require a humid atmosphere when cultivated at $37^{\circ}$. Oxidase reaction positive. Most strains are strongly or moderately sensitive to penicillin. Parasitic.'

Such a description would keep the genus reasonably homogeneous and prevent inclusion of organisms that, apart from morphological similarity, have little relationship to the original species. Some of the strains studied by Piéchaud et al. (1951) would have to be excluded, since one of their strains, which is probably included in this study (M. pericardite), did not belong to the oxidase-positive group; others were strains of the species Bacterium anitratum or the B 5 W group of Stuart, Formal \& McGann (1949).

It is suggested that the division of the genus might follow the proposals of Lwoff (1939), by which one would recognize the species lacunata and duplex 
(with the variety nonliquefaciens). It has been shown in this study that at least some strains of these species possess the additional characteristics referred to before. The position of the strains isolated from eye inflammations in cattle (M. bovis in Bergey's Manual, 1948) is not clear. There is little evidence to show whether these strains differ sufficiently from the other species to deserve recognition as a separate species. In contrast to the other species these strains are reported to be haemolytic.

As for the species Iwoffi, proposed by Audureau (1940), the fact that the only strain of this species that was available for examination (M. lwoffi var. bacteroides) differed from the oxidase-positive group, makes it desirable to re-examine other strains of the species. Of the strains isolated in this laboratory, two (6768/51 and 7146/51) grew fairly well in Audureau's defined medium, and thus might be classified as $M$. lwoffi, if this species is considered valid. One strain showed only a trace of growth in this medium and three strains refused to grow. Thus it seems that there may be gradual transitions between positive and negative strains. In other respects these six strains appeared to be similar, and it seems questionable whether differences in this single characteristic would justify the establishment of separate species. The significance of this characteristic, as well as the validity of the species lwoffi, should be reconsidered after further studies have been carried out.

Not only the description of the genus but also its taxonomic position may need revision, as suggested by Lwoff (1939). If need for either the $V$ or the $X$ factor is considered essential for inclusion in the Haemophileae, Moraxella has no natural place in this tribe. Only one of the species requires media enriched with body fluids, but is independent of the $\mathbf{V}$ and $\mathbf{X}$ factors, and the other species grow on simple media and even on a defined medium containing only citrate, ethanol, ammonia and salts. Therefore there seems to be little reason to retain Moraxella in the Haemophileae. Furthermore, all strains were characterized by comparatively plump, broad cells, coarser than those found in the Parvobacteriaceae (when the involution forms produced by some of the latter are disregarded). There appears to be no other strong argument for the inclusion of Moraxella in this family.

Two courses of action might be followed. If the evidence for inclusion of Moraxella in some other family be found insufficient, the genus might be placed temporarily in the Bacteriaceae until its final place could be agreed upon. Or one might try to find another family to which Moraxella shows relationship; in this case Neisseriaceae might be the best choice, as the following comparison shows :

Neisseria

Coffee-bean shaped diplococci

Shape of cells

Size

Staining
Often plump, but with considerable variation in many strains. Large swollen cells occur

Gram-negative. Often irregular with strongly stained and pale cells
Moraxella

Short diplobacilli or coffeebean shaped diplococci Plump with considerable variation. Large swollen cells frequent

Gram-negative. Often irregular with strongly stained and pale cells. Some cells tend to resist decolorization 


\begin{tabular}{|c|c|c|}
\hline & Neisseria & Moraxella \\
\hline Colonies & $\begin{array}{l}\text { In some species soft, colour- } \\
\text { less. In others friable or } \\
\text { viscous, grey or greyish } \\
\text { white or pigmented. Small } \\
\text { or moderate size }\end{array}$ & $\begin{array}{l}\text { In some strains colourless, } \\
\text { soft, in others friable or } \\
\text { viscous, grey to yellowish } \\
\text { grey. Small or moderate } \\
\text { size }\end{array}$ \\
\hline Growth & $\begin{array}{l}\text { Some species require body } \\
\text { fluids, others grow in simple } \\
\text { media. Some species prefer } \\
\text { a humid atmosphere at } 37^{\circ}\end{array}$ & $\begin{array}{l}\text { One species requires body } \\
\text { fluids, others grow on simple } \\
\text { or defined media. Some } \\
\text { strains prefer or require a } \\
\text { humid atmosphere at } 37^{\circ}\end{array}$ \\
\hline Oxidase reaction & Positive & Positive \\
\hline Penicillin sensitivity & $\begin{array}{l}\text { Some species strongly sensi- } \\
\text { tive, others moderately sen- } \\
\text { sitive or slightly resistant }\end{array}$ & $\begin{array}{l}\text { Strongly or moderately sensi- } \\
\text { tive }\end{array}$ \\
\hline Habitat & $\begin{array}{l}\text { Parasites in the respiratory } \\
\text { or genito-urinary tract }\end{array}$ & $\begin{array}{l}\text { Parasites in the respiratory } \\
\text { or genito-urinary tract }\end{array}$ \\
\hline Pathogenicity & $\begin{array}{l}\text { Some species cause inflam- } \\
\text { mations on mucous mem- } \\
\text { branes. }\end{array}$ & $\begin{array}{l}\text { Some species cause inflam- } \\
\text { mations on mucous mem- } \\
\text { branes }\end{array}$ \\
\hline
\end{tabular}

It is not likely that these similarities are entirely the result of coincidence, although the significance of all the characters given in the list may not be equally high. The only significant difference between the two genera is that one exclusively consists of cocci, and the other mostly of rods. Some strains of Moraxella, however, show such close resemblance to Neisseria that great care has to be exercised to avoid mistakes. Objection might be raised to the inclusion of rod-shaped and coccus-shaped organisms in the same family, but there is precedence for such an arrangement in the Lactobacteriaceae. It seems that the relationship between Moraxella and Neisseria may perhaps be as close as that between the tribes Streptococceae and Lactobacilleae. Before this proposal can be accepted the results reported here will have to be corroborated and extended by others, but it is suggested that the relationship between the two genera should be kept in mind.

The relationship of Moraxella to certain other organisms remains to be discussed. De Bord (1939, 1942, 1943, 1948) proposed a new tribe, Mimeae, composed of organisms showing morphological resemblance to neisseria. They were further characterized by pleomorphism, a tendency to retain the Gram stain and encapsulation. The genus Mima does not ferment carbohydrates, Herellea produces acid, and Colloides acid and gas from various sugars. Apart from these biochemical differences the three genera and their species (Mima polymorpha with the variety oxidans, Herellea vaginicola and Colloides anoxydana) are described with the same words, indicating that the other characters are identical. An analysis of these descriptions suggests the following considerations :

(i) The oxidase-positive variety of Mima polymorpha may be indistinguishable from Moraxella duplex var. nonliquefaciens (Lwoff, 1939). If so, the name suggested by De Bord would be invalid, as the relationship of this organism to the Morax-Axenfeld group had been recognized long before De Bord's paper appeared, even though De Bord's and Lwoff's papers both appeared in the same year. 
(ii) The description of Mima polymorpha is the same as that of the variety oxidans, apart from the negative oxidase reaction. It may be suggested that more differences might have been found if the characters reported in this paper had been studied. It is impossible at present to decide where $M$. polymorpha belongs, and further studies are necessary. It is suggested that this species should not be included in the genus Moraxella until its properties have been re-examined.

(iii) Herellea shows considerable resemblance to Bacterium anitratum Schaub \& Hauber (1948) or the B 5 W group described by Stuart, Formal \& McGann (1949) and by Ferguson \& Roberts (1950). Some strains isolated by Deacon (1945) and believed to be Herellea species, showed even greater resemblance to these organisms, as they fermented the same carboyhdrates, whereas De Bord's strains showed different fermentation reactions. This led Ewing (1949) to suggest a relationship between Mimeae, Herellea in particular, and Bacterium anitratum. Apart from morphological similarity there is no evidence to show that these organisms should be included in Moraxella as defined in this paper. Bact. anitratum is known to be resistant to penicillin (Schaub \& Hauber, 1948) and has not been reported to be oxidase-positive. Piéchaud et al. (1951) have expressed a different opinion, as they consider the B 5 W group belongs to $M$. lwoffi.

(iv) Colloides gives exactly the same biochemical reactions as Esch. freundii (Bergey's Manual, 1948), and the unusual morphology appears to be the only reason for separating it from the latter species. Diplococcus-like cells in strains of various Enterobacteriaceae are not uncommon, and the grounds for establishing the genus Colloides may, therefore, be weak.

It is concluded that Mima polymorpha var. oxidans may belong to Moraxella, but the relationship of the other organisms mentioned will have to be decided when better evidence becomes available. It is felt that whereas morphological characters are very useful in bacterial classification in distinguishing between the larger taxonomic groups, over-emphasis on morphological details may lead to erroneous conclusions. This is particularly true of morphological characters which may be found more or less frequently in a number of widely separated taxonomic groups.

I am indebted to Dr A. Lwoff and Dr M. Piéchaud for strains of Moraxella and for friendly advice.

\section{REFERENCES}

Audureau, A. (1940). Étude du genre Moraxella. Ann. Inst. Pasteur, 64, 126. Bergey's Manual of Determinative Bacteriology (1948). 6th ed. edited by Breed, R. S., Murray, E. G. D. \& Hitchens, A. P. Baltimore: Williams and Wilkins Co. Cashell, G. T. W. (1944). Treatment of ocular infections with penicillin, Brit. med. J. i, 420.

Deacon, W. (1945). A note on the tribe Mimeae (De Bord). J. Bact. 49, 511.

DE BoRD, G. G. (1939). Organisms invalidating the diagnosis of gonorrhoea by the smear method. J. Bact. 38, 119. 
DE BoRD, G. G. (1942). Descriptions of Mimeae trib. nov. with three genera and three species and two new species of Neisseria from conjunctivitis and vaginitis. Iowa St. Coll. J. Sci. 16, 471.

DE Bord, G. G. (1943). Studies on the tribes Mimeae, Neisserieae and Streptococcaceae which confuse the diagnosis of gonorrhoea by smears. J. Lab. clin. Med. $28,710$.

De Bord, G. G. (1948). Mima polymorpha in meningitis. J. Bact. 55, 764.

Dubos, R. J. (1949). The Bacterial Cell, p. 296. Cambridge, Mass.: Harvard University Press.

Ewing, W. E. (1949). The relationship of Bacterium anitratum and members of the tribe Mimeae (De Bord). J. Bact. 57, 659.

Ferguson, W. W. \& Roberts, L. F. (1950). A bacteriological and serological study of organism B5 W (Bacterium anitratum). J. Bact. 59, 171.

Florey, H. W., Chain, E., Heatley, N. G., Jennings, M. A., Sanders, A. G., Abraham, E. P. \& Florey, M. E. (1949). Antibiotics, II, pp. 996-1023. London: Oxford University Press.

HenRIKsen, S. D. (1947). Gram-negative diplo-bacilli from the genito-urinary tract. Acta path. microbiol. scand. 24, 184.

Henriksen, S. D. (1951). Moraxella duplex var. nonliquefaciens as a cause of bronchial infection. Acta path. microbiol. scand. 29, 258.

Jensen, K. A. \& Kiaer, I. (1948). Problems concerning the estimation of the chemosensitivity of microbes and measuring of penicillin and streptomycin concentrations in the blood and spinal fluid. Acta path. microbiol. scand. 25, 146.

Lund, E., Funder-Schmidt, H., Christensen, H. \& Dupont, A. (1951). Sensitivity test with the tablet method. Acta path. microbiol. scand. 29, 221.

Lwoff, A. (1939). Revision et démembrement des Hemophilae, le genre Moraxella nov. gen. Ann. Inst. Pasteur, 62, 168.

Mruner, J. G. (1944). Penicillin in ophthalomology. Brit. med. J. ii, 175.

Oeding, P. (1946). Diplobacillus liquefaciens Petit, isolated from a patient with an ulcus serpens corneae. A description of the microbe, with a historical survey and discussion on the classification of the diplobacilli. Acta ophthal., Kbh. 24, 159.

Piéchaud, D., Piéchaud, M. \& Second, L. (1951). Étude de 26 souches de Moraxella lwoffi. Ann. Inst. Pasteur, 80, 97.

SchaUb, I. G. \& HaUber, F. D. (1948). A biochemical and serological study of a group of identical Gram-negative bacilli from human sources. J. Bact. 56, 379.

SorsBy, A. (1945). Local penicillin therapy in ophthalmia neonatorum. Brit. med.J. i, 903.

Steen, E. \& Berdal, P. (1950). Chronic rhinosinusitis caused by Moraxella liquefaciens Petit. Acta oto-laryng., Stockh. 38, 31.

Stuart, C. A., Formal, S. \& McGann, V. (1949). Further studies on B5 W, an anaerogenic group in the Enterobacteriaceae. J. infect. Dis. 84, 235.

\section{EXPLANATION OF PLATE}

Figs. 1-5 are living cells examined by phase contrast microscopy. Figs. $6-9$ are cells stained by Gram's method with safranin as counter stain.

Fig. 1. M. duplex var. nonliquefaciens, strain $283 / 49$. Nearly exclusively cocci, measuring c. $1 \cdot 3-1 \cdot 5 \mu \cdot \times 1 \cdot 3-1 \cdot 7 \mu . \times 3600$.

Fig. 2. M. duplex var. nonliquefaciens, strain 3452/51 (mucoid). Rods measuring c. 1·1-1.2 $\mu$. $\times 2-3.5 \mu . \quad \times 2800$.

Fig. 3. M. lwoffi var. bacteroides. Cocci and short rods measuring $c .0 \cdot 6-1 \mu \cdot \times 0 \cdot 8-2 \cdot 2 \mu$. $\times 2500$.

GM VI 3 \& 4 
Fig. 4. $M$. duplex var. nonliquefaciens, strain OT 1/51. Short plump rods measuring c. 1.2-1.6 $\mu . \times 1.4-2.6 \mu . \times 2500$.

Fig. 5. M. duplex var. nonliquefaciens, strain 6768/51. Short diplobacilli measuring c. $1-1 \cdot 1 \mu . \times 1 \cdot 4-2 \cdot 2 \mu . \quad \times 2500$.

Fig. 6. M. duplex var. nonliquefaciens, strain $283 / 49 . \times 1250$.

Fig. 7. Neisseria catarrhalis, strain TT/51. Note striking similarity to fig. $6 . \times 1250$.

Fig. 8. Diplobaccillus of Morax, strain 260. $\times 1250$.

Fig. 9. M. duplex var. nonliquefaciens, strain 676851. $\times 1250$.

(Received 15 October 1951) 
Journal of General Microbiology, Vol. 6, Nos. 3 and 4
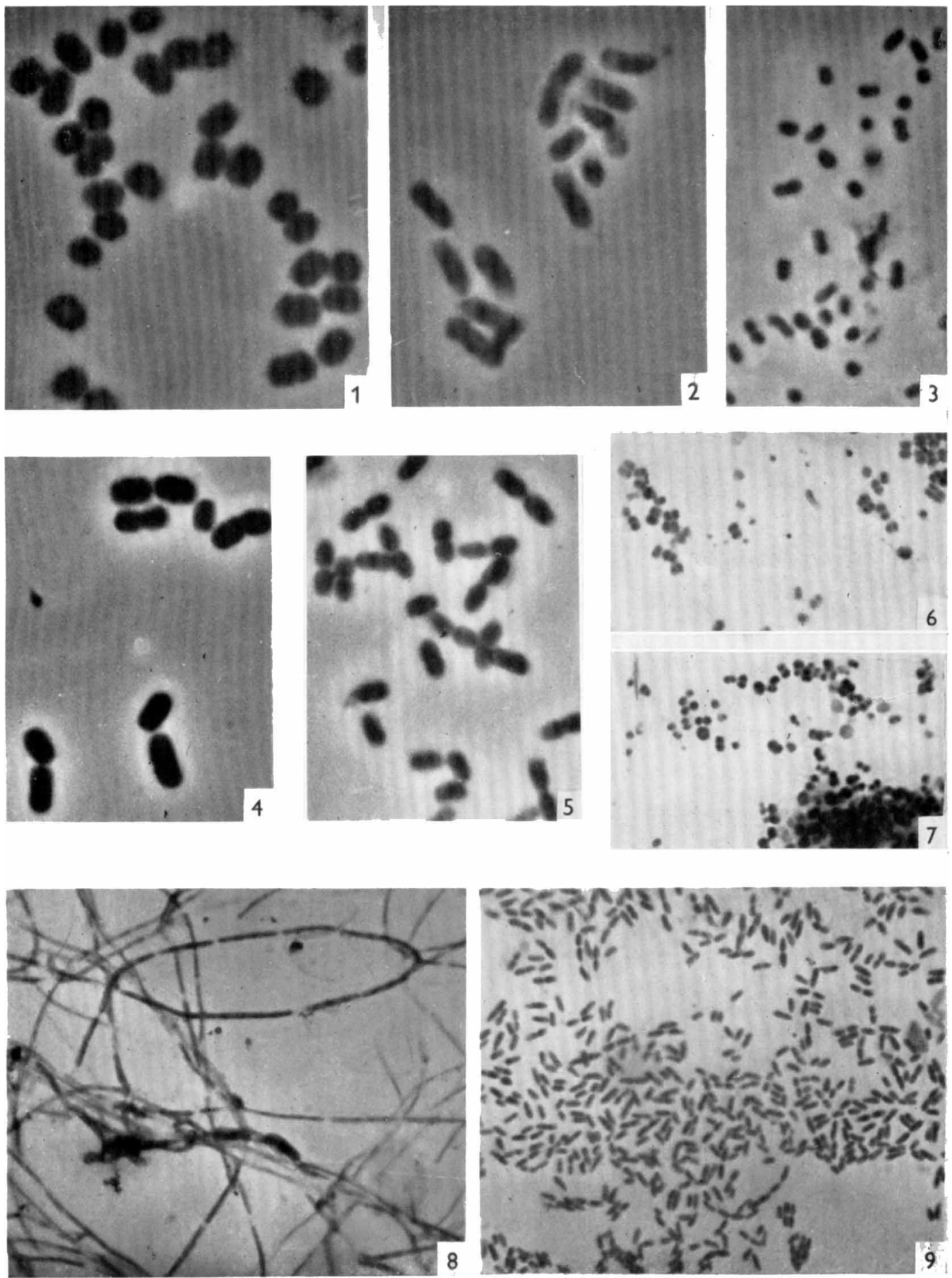

S. D. Henriksen-Moraxella : Classification and taxonomy. Plate 1 